\title{
ФОРМЫ ВОЗДЕЙСТВИЯ НА СОСТОЯНИЕ РЫНКА ИННОВАЦИОННОЙ ПРОДУКЦИИ С УЧЕТОМ ПРОЦЕССОВ НЕОИНДУСТРИАЛИЗАЦИИ
}

\author{
(c) 2020 Бадртдинов Наиль Нагимович \\ старший преподаватель \\ Казанский (Приволжский) федеральный университет, Россия, Казань \\ E-mail: Nail.Badrtdinov@kpfu.ru
}

В статье приведены результаты анализа методологии исследования деятельности субъектов технологического предпринимательства на макроуровне. В связи со вступлением нашей страны в ВТО и глобализацией мировой экономики происходят значительные изменения основных экономических характеристик внешней среды, влияющих на деятельность производственных предприятий. K важнейшим из них относятся: усложнение продукции; повышение требований к качеству продукции; появление индивидуальных требований к продукции; ужесточение конкуренции на рынке продукции. В исследовании проведен обзор наиболее релевантных зарубежных исследований в этой сфере. В российской экономической литературе в последнее время уделяется значительное внимание проблеме формирования экономики инновационного типа. В тоже время статистические исследования, посвященные выделению ключевых факторов инновационной активности и оценке их влияния на деятельность российских предприятий или регионов довольно немногочисленны. В большинстве случаев подобные исследования ограничиваются обобщенным рассмотрением динамики инновационной активности в промышленности. Насколько нам известно, факторы инновационной активности на региональном уровне еще не были изучены. По итогам исследования сделаны выводы о преобладании моделирования, методов статистического анализа и феноменологического метода в качестве доминирующих методологических подходов к исследованию технологического предпринимательства.

Ключевые слова: методология, инновации, макроэкономика, экономический рост, технологическое предпринимательство.

В современной экономической теории инновации считаются одним из механизмов обеспечения устойчивого экономического роста в долгосрочной перспективе. Процессные инновации рассматриваются как необходимое условие для повышения производительности труда, продуктовые инновации - как инструмент повышения конкурентоспособности предприятий в условиях изменяющейся экономической среды, а также как способ решения социально-экономических и экологических проблем. Положительное влияние инноваций на усиление конкурентоспособности национальных экономик послужило основным мотивом для разработки странами с развитой экономикой ряда мер, направленных на стимулирование инновационной активности.

Классические подходы инновационного менеджмента определяют первым этапом функциональной последовательности инновационного процесса фундаментальные исследования, которые генерируют новые научные знания. Признавая справедливость этого утверждения, следует отметить, что с точки зрения конкретного предприятия-инноватора оно является довольно абстрактным. Рынок диктует свои условия, и инновации могут появиться только там и тогда, где для этого есть объективные условия.

Обобщение результатов анализа стало основанием для формирования первоочередных задач маркетинга инноваций, которые необходимо срочно решать.

1. Совершенствование критериальной базы и теоретико-методических подходов к оценке рыночной адекватности идей и замыслов товарных инноваций. Как ориентировочные, могут быть предложены критерии, которые позволяют получить ответы на следующие вопросы:

2. Разработка теоретических основ и методического инструментария анализа рынка для новых товаров, тех, которые предназначены для удовлетворения скрытых (неосознанных) потребностей потребителей, и особенно тех, которые формируют новые потребности. Целесообразным представляется ориентировать такие разработки на анализ и оценку разного рода рыночных барьеров, которые усложняют или дела- 
ют невозможным восприятие инновационных товаров.

3. Совершенствование метода пробного маркетинга в части повышения уровня формализации с целью обеспечения надежности и достоверности рыночных испытаний товара.

4. Разработка теоретико-методических основ формирования первичного спроса и управления стратегиями продвижения радикальных товарных инноваций на рынок, а также рационального распределения коммуникационных инструментов комплекса продвижения для избранных стратегий, включая распределение затрат на эти инструменты. Для улучшающих инноваций с большой степенью наследования базовых товаров такие разработки существуют, их можно принять за основу.

5. Совершенствование теоретических основ и методического инструментария управления бизнес-портфелем инновационных товаров и товарной инновационной политикой вообее. В частности, на уровне товарной номенклатуры, товарных линий, отдельных товарных единиц. Необходимой является разработка подходов к рационализации управления жизненным циклом товарных инноваций. Систематизация и обобщение имеющихся разработок должны стать отправной точкой формирования формализованных процедур управления товарной инновационной политикой предприятия.

6. Формирование и обоснование комплекса рекомендаций относительно выбора стратегий ценообразования для товарных инноваций разной степени новизны для рынка и товаропроизводителя.

7. Разработка теоретико-методических основ выбора оптимальной организационной структуры маркетинга инноваций в зависимости от специфики предприятия, условий хозяйствования на рынке, особенностей инноваций. Существует много типов организационных структур предприятий инновационного бизнеса, которые «привязаны» к этапам инновационного цикла, уровню риска, прогнозируемым объемам сбыта инновационной продукции, однако отсутствуют чёткие однозначные рекомендации относительно выбора конкретных структур.

8. Совершенствование системы планирования маркетинга инноваций, особенно радикальных инноваций. Имеющиеся наработки дают лишь ориентировочные рекомендации относительно общего содержания планирования на стратегическом, тактическом и оперативном уровнях. Эти наработки могут быть взяты за основу при разработке системы планирования маркетинга инноваций, которая соответствует условиям внешней и внутренней среды хозяйствования с учетом тенденций их изменения.

9. Разработка механизма оценки результативности (с учетом риска) на ранних стадиях инновационного процесса (инновационного цикла). Существует довольно много методов оценки риска и его учета при оценке результатов инновационной деятельности, однако практически ни один из них, отдельно взятый, е дает приемлемых результатов, поскольку учитывает лишь отдельные факторы риска. Очевидно, необходимо разработать алгоритм выбора оптимального сочетания различных методов анализа риска, а также процедуры оценки на разных этапах инновационного цикла.

В условиях быстрых изменений на рынке и дефицита финансовых ресурсов на проведение такого рода оценок может просто не хватить ни времени, ни средств. Поскольку ситуация на рынке может коренным образом измениться, и имеющиеся на текущий момент рыночные возможности будут, в первую очередь, реализованы теми, кто сумел оперативнее их выявить и использовать.

Поэтому, признавая несомненную необходимость детального экономического анализа и оценки принятых решений согласно общепризнанным методикам, следует отметить, что предварительный отбор вариантов необходимо выполнять другими способами, оперативно и с минимальными затратами. Тем более, если таких вариантов окажется довольно много.

Учитывая реалии современной рыночной экономики, когда большей властью обладают потребители, а производители должны ориентировать свою деятельность на удовлетворение их потребностей и запросов, важную роль играет мотивация (стимулирование) потребления новой (в том числе экологической) продукции. Наличие мотивации потребления при отсутствии дефицита товаров и наличия острой конкуренции товаропроизводителей приводит к тому, что покупаться будет лишь та продукция, которая отвечает потребностям и запросам потребителей. Можно стимулировать производство продукции, но если её преимуществ не оценят потребители, то все усилия окажутся напрасными. Потребители в большинстве случаев довольно настороженно относятся к новой продукции (новым технологиям), а экологические товары 
являются таковыми, проявляют при этом определенный консерватизм относительно них. Поэтому мотивации потребления следует уделять особое внимание. Это означает, что, принимая решение о разработке экологического товара, всегда следует анализировать, существуют ли мотивы, которые подталкивают потребителей к его приобретению? Если таких мотивов нет, то следует серьезно призадуматься о целесообразности разработки товара, необходимо оценивать эффективность формирования соответствующих побудительных мотивов (стимулирования потребления) путем сравнения прогнозируемых расходов на проведение соответствующих мероприятий и ожидаемых результатов от внедрения экологического товара.

Спрос на экологические товары (кстати, как и спрос на традиционные товары) нуждается в определенных усилиях по его формированию и стимулированию.

Мотивы потребления экологических товаров (изделий и услуг) неравнозначны. По силе влияния их можно ранжировать следующим образом: рациональные, эмоциональные, моральные. Последние являются действенными, прежде всего, в экономически развитых странах с высоким уровнем «качества жизни», т.е. в тех, где экономические проблемы общества, в основном, решены. В отечественных условиях упор следует делать на рациональные мотивы, не оставляя при этом без внимания эмоциональные и моральные.

Вследствие разных причин (высокой себестоимости чистого сырья, необходимого для изготовления экологических товаров; применения дорогостоящего оборудования; большого объема научно-исследовательских работ и др.) цена экологической продукции во многих случаях более высокая, чем цена аналогичной традиционной продукции. Но потребители, особенно с низкой платежеспособностью, не всегда готовы заплатить дополнительную цену за экологичность товаров.

Поэтому для успешного продвижения экологических товаров на рынке необходимым является создание соответствующего механизма мотивации. Для достижения потенциальными покупателями состояния осуществления покупки предприятию необходимо формировать у потребителей знания относительно преимуществ экологических товаров, их уникальности, проводить рекламу конкретных экологических товаров, демонстрировать соотношение коэф- фициентов качества и цены экологических и традиционных товаров (для убеждения покупателей в «справедливости» цены), а также применять другие методы стимулирования потребления и сбыта.

В условиях невысокого качества жизни особенно важным является информирование покупателей об экономической целесообразности потребления или эксплуатации экологических товаров. Покупатели должны осознать, что экологичность - очень важный показатель качества товара, что покупка более дорогих экологических товаров окупается, т.е. осознавать известную мысль, что «мы не настолько богатые, чтобы покупать дешевые вещи». Так, употребление экологически чистых продуктов питания, использование экологической посуды для приготовления пищи, качественных фильтров для очистки питьевой воды оказывает содействие улучшению состояния здоровья. Соответственно уменьшаются расходы на лекарства и лечебные мероприятия. Это касается также экологических материалов и оборудования для производства и быта, например, использование экологически чистых обоев, эксплуатация компьютерных мониторов на жидких кристаллах вместо обычных с электронно-лучевой трубкой и др. Эксплуатация автомобиля с инжекторным двигателем не только снижает загрязнение окружающей природной среды, но и реально экономит деньги его владельца. Установка очистного оборудования позволяет снизить суммы платежей и штрафов за загрязнение и др.

Особенностью экологических товаров является то, что, кроме базовой функции, они всегда выполняют и дополнительные функции. Так, для экологических продуктов питания это могут быть лечебные, профилактические функции и др.

Для оценки спроса на экологические товары могут быть использованы традиционные подходы. Однако есть и определенные отличия.

По отношению к экологическим товарам можно выделить следующие группы потребителей:

1. Потребители, которые не хотят покупать экологический товар. Например, вегетарианцы при оценке спроса на экологически чистые мясные продукты; абстистенты (непьющие) при определении спроса на ликеро-водочные изделия с экологически чистыми ингредиентами.

2. Потребители, которые не могут использовать экологические товары. Например: люди, 
которым состояние здоровья не позволяет потреблять экологические товары с определенными ингредиентами.

3. Потребители, которые не определили своё отношение к экологическому товару.

4. Потребители, готовые к приобретению экологического товара данного наименования по определенной цене с определенными потребительскими качествами.

Для обеспечения конкурентоспособности экологических товаров предприятию необходимо обладать информацией о новых экологических технологиях, а также иметь соответствующее оборудование. Его приобретение по обыкновению сопровождается значительными расходами. Поэтому для начала производитель экологических товаров должен иметь значительную финансовую базу или же возможность получения кредитов на приемлемых условиях.

Среди особенностей экологических товаров можно назвать ту, что часто похожие на обычные аналоги экологические товары являются уникальными. Поэтому для привлечения потребителей производитель экологических товаров, аналоги которых есть на рынке, должен предоставлять потребителям информацию об уникальности своих товаров и использовать методы мотивации потребителей, отличающиеся от методов, применяемых конкурентамипроизводителями обычных аналогов.

То есть нужно заострять внимание потребителей не только на прямой экономической целесообразности потребления экологической продукции, но и на побочных её эффектах.

Эта информация, особенно если она подается в независимых источниках, например, обзорных статьях известных специалистов, воспринимается, как более достоверная, чем прямая реклама, и вызывает большее доверие потребителей.

К стимулированию сбыта относят традиционные мероприятия (предоставление скидок или определенных льгот, кредитование, лизинг дорогих изделий, предоставление безвозмездных образцов изделий, лотереи, конкурсы и т.п.), которые направлены на потребителя или продавца продукции (посредника) и которые в полной мере могут и должны быть использованы для стимулирования спроса на экологическую продукцию.

Особенности рынка инновационной продукции и специфика его функционирования в условиях разработки и реализации стратегии неоиндустриализации российской экономики определяют необходимость уточнения состава методов его регулирования со стороны государства. Наряду с традиционными инструментами, используемыми государством для выполнения возложенных на него функций в соответствии с положениями теории общественного благосостояния, выявленные особенности данного сегмента рынка обусловливают необходимость использования дополнительных мер воздействия. Содержание последних определяется множеством факторов, среди которых особое значение имеет доминирующий тип инновационного цикла и субъектный состав рыночных агентов.

В случае, если инновационная продукция выступает результатом реализации интерактивной модели инновационного цикла и инициируется в равной степени потребителями или научноисследовательские организации (подразделения в составе предпринимательских структур), то государству целесообразно использовать меры, направленные на стимулирование потребительских расходов (например, на экологически чистую продукцию, произведенную в рамках реализации стратегии импортозамещения). В свою очередь, в их составе выделяются меры, ориентированные на имплантацию в состав нормативных ценностей потребителя («новаторов» и «пионеров освоения») представлений, соответствующих стратегии неоиндустриализации российской экономики, что предполагает необходимость использования потенциала образовательных и самообучающихся организаций. В отношении «раннего большинства», «позднего большинства» и «медлительных» целесообразно применять меры, направленные на увеличение спроса с использованием эффекта дохода и эффекта замещения (социальные налоговые вычеты, государственное регулирования цен на инновационную продукцию и товары-субституты, компенсации по программе утилизации автомобилей и др.).

В случае, если инновационная продукция выступает результатом реализации сетевой модели инновационного цикла, использующей ориентированную на потребителя стратегию, то государству целесообразно использовать инструменты институционального проектирования, направленные на преодоление институциональных ловушек. Это, в свою очередь. предполагает разработку нормативных правовых актов, определяющих критерии отнесения продукции к числу инновационной; меры, на- 
правленные на сетивизацию экономического пространства и активизацию взаимодействия субъектов предпринимательства в рамках интегрированных образований (кластеров и др.) и в на уровне национальной экономики в целом; снижение транзакционных издержек защиты правомочий интеллектуальной собственности, мониторинга результатов инновационных проектов и др. (например, маркировка нанопродукции с целью улучшения качества информирования потребителей, развитие наукоградов, инновационных центров, технопарков и др.).

В случае, если инновационная продукция выступает результатом реализации информационной модели инновационного цикла, направленной на накопление и передачу явного (кодифицированного) знания, то государству целесообразно использовать инструменты, направленные на накопление и эффективную реализацию человеческого капитала, снижение асимметрии информации (например, услуги электронного правительства и др.).

Реализация предложенного подхода к содержанию методов государственного регулирования инновационной продукции обеспечивает проведение системных преобразований, на- правленных на формирование цепочек добавленной стоимости, повышение рентабельности внутреннего производства, сокращение издержек, оптимизацию и диверсификацию структуры национальной экономики в рамках стратегии неоиндустриализации.

Сравнительный анализ состояния рынков инновационной продукции в РФ и за рубежом показывает, что одним из факторов, препятствующих формированию эффективного спроса в данном сегменте, выступает наличие значительного числа институциональных ловушек. Формирование и функционирование подобных неэффективных институтов связано с противоречивостью интересов потребителей и производителей (продавцов), а также противоречием между долгосрочными и краткосрочными интересами участников рынка.

Институциональные ловушки могут быть преодолены в результате эволюционных или революционных трансформаций составляющих институциональной среды, вызванных превышением транзакционных издержек функционирования неэффективного института над трансформационными издержками отмены действующего и/или введения нового института.

\section{Библиографический список}

1. Кундакчян Р.М., Григорьева Н. С., Зульфакарова Л.Ф. Современные тенденции использования института импортозамещения на российском рынке информационных технологий // Труды Вольного экономического общества России. - 2017.- № 2.-С. 367-379.

2. Курегян С.В., Елкина О. С., Елкин С. Е. Инновационная экономика и экономика инноваций // Экономическая наука сегодня. - 2018. - № 8.- С. 100-107.

3. Курегян С.В. Экономические характеристики интеллектуального производства // Экономическая наука сегодня.-2018. - № 8.- С. 100-107.

4. Коростышевская Е.М., МиэриньЛ.А., Фахрутдинова Е.В. Инновационная система ЕС и место России в европейском инновационном пространстве.-Современное искусство экономики. 2015. № 2 (20). С. $59-67$.

5. Пастухов А.Л. Модернизационный экономический рост на основе формирования образовательных кластеров // Экономическая наука сегодня. - 2017. - № 9.- С. 169-177.

6. Bailetti T. Technology Entrepreneurship: Overview, Definition, and Distinctive Aspects // Technology Innovation Management Review.-2012.- Volume 2, Issue 2.- Pp. 5-12.

7. Astebro T. Key success factors for technological entrepreneurs' R\&D projects // IEEE Transactions on Engineering Management.-2004.- Volume 51, Issue 3.-Pp. 314-321.

8. Shan S., Jia Y., Zheng X., XuX. Assessing relationship and contribution of China's technological entrepreneurship to socio-economic development // Technological Forecasting and Social Change. - 2018. - Volume 135. - Pp. 8390.

9. Vasil'ev Y.S., Zegzhda D.P., Poltavtseva M.A. Problems of Security in Digital Production and Its Resistance to Cyber Threats // Automatic Control and Computer Sciences. - 2018._- Volume 52, Issue 8._ Pp. 1090-1100.

10. Komkov N.I., Kulakin G. K. Technological Innovations: Development, Application and Results // Studies on Russian Economic Development. - 2018. - Volume 29, Issue 5.- Pp. 558-572.

11. Bogomolova, T.Y., Fadeeva, O.P., Faleychik, L.M., Shvorina, K.V. Reindustrialization of the Rural Economy in Zabaikalskii Krai: Pitfalls and Possibilities // Regional Research of Russia.-2018.- Volume 8, Issue 3.- Pp. 258-268.

12. Фахрутдинова Е.В., Мокичев С. Д. Проблемы методологии в развитии и модернизации экономики.- Экономические науки. 2015. № 122. С. 11-14. 